Wiersinga WM, Kahaly GJ (eds): Graves' Orbitopathy: A Multidisciplinary Approach - Questions and Answers. Basel, Karger, 2010, pp 248-254

\title{
Prevention
}

\section{Luigi Bartalena}

Division of Endocrinology, Department of Clinical Medicine, University of Insubria, Ospedale di Circolo, Varese, Italy

Prevention of a disease is always preferable to its treatment. This is particularly true for Graves' orbitopathy (GO) as approximately one third of affected patients are, at the end of treatment, dissatisfied with their physical appearance and residual functional abnormalities [1].

\section{What Is Primary, Secondary and Tertiary Prevention?}

Prevention may be primary, secondary, or tertiary [2]. Primary prevention of a disease is aimed at avoiding its occurrence by removing risk factors; secondary prevention refers to early diagnosis and treatment of subclinical, asymptomatic disease, to prevent its progression toward clinically overt disease; tertiary prevention encompasses all actions taken after the occurrence of clinical disease, to minimize the risk of disease-related complications and disability. Distinction of these different stages may be difficult and, in some instances, arbitrary. For example, normalization of blood pressure in hypertensive patients may be a secondary prevention of hypertensive heart disease and, at the same time, primary prevention of myocardial infarction or stroke. Nevertheless, classification of prevention into different levels maintains its usefulness, underscoring the need for: (1) modification/abolishment of risk factors, (2) recognition of subclinical disease, and (3) early treatment of initial clinical manifestations.

\section{Can a General Strategy Be Applied to Prevent Graves' Orbitopathy?}

GO is a multifactorial disorder, resulting from a complex interplay of endogenous and environmental factors [3]. The former (poorly understood genetic factors, age, gender) are, by definition, non-preventable; the latter (smoking, thyroid dysfunction, 
Table 1. Prevention of Graves' orbitopathy

\begin{tabular}{llll}
\hline Stage & Prevention & Goal & Actions \\
\hline Absent disease & primary & $\begin{array}{l}\text { avoid occurrence } \\
\text { of disease }\end{array}$ & refrain from smoking \\
\hline $\begin{array}{l}\text { Subclinical } \\
\text { disease }\end{array}$ & secondary & $\begin{array}{l}\text { prevent progression } \\
\text { and clinical disease }\end{array}$ & $\begin{array}{l}\text { refrain from smoking } \\
\text { restoration of euthyroidism } \\
\text { selenium administration } \\
\text { prudent use of radioiodine }\end{array}$ \\
\hline Clinical disease & tertiary & avoid complications \\
and minimize disability & $\begin{array}{l}\text { local measures } \\
\text { medical or surgical treatment of orbitopathy } \\
\text { rehabilitative surgery }\end{array}$
\end{tabular}

and, under certain circumstances, radioiodine therapy for hyperthyroidism) are preventable $[4,5]$. It is unknown why only $3-5 \%$ of patients with Graves' disease develop severe orbitopathy, about half have only mild eye disease, and the remaining patients apparently have no ocular involvement. This might reflect the fact that environmental factors are more important than endogenous factors. Thus, a general strategy can be devised to act on environmental factors. In other words, medical intervention can effectively influence GO course, by strongly urging patients to refrain from smoking, properly correcting thyroid dysfunction, using radioiodine cautiously, and treating moderate-to-severe GO as early as possible $[4,5]$ (table 1 ).

\section{What Can Be Done in the Primary Prevention of Graves' Orbitopathy?}

Smoking withdrawal is the only primary prevention measure for GO. Smoking is associated with Graves' hyperthyroidism. In the Nurses' Health Study II on more than 115,000 women aged 25-42 years, cigarette smoking was a predictor of Graves' hyperthyroidism, with a hazard ratio of 1.93 in current smokers, 1.27 in former smokers, and 2.63 in heavy smokers ( $>25$ cigarettes/day) [6]. In a case-control study, the odds ratio of smoking for Graves' hyperthyroidism without ocular involvement was 1.7 , but increased to 7.7 for Graves' hyperthyroidism with associated orbitopathy [7]. The odds were even higher in patients with more severe orbitopathy. In a large cross-sectional study, the prevalence of smokers among women with Graves' hyperthyroidism and orbitopathy (64\%) was significantly higher than that in Graves' women apparently without ocular involvement (48\%) or in normal controls (about 30\%) [8] (table 2). According to a European Thyroid Association (ETA) survey, GO incidence decreased in the last decade for $43 \%$ of respondents and increased for $12 \%$ : most respondents in the first group came from European countries with a declining 
Table 2. Smoking effects on Graves' hyperthyroidism and orbitopathy

Increased risk of development of Graves' disease in smokers

Increased relapse rate of hyperthyroidism after antithyroid drug treatment in smokers

Increased prevalence of smokers in adult Graves' orbitopathy patients as compared to Graves' patients without orbitopathy or controls

Increased prevalence of Graves' orbitopathy in children from countries with the highest prevalence of smoking teenagers (with possible role of passive smoking as well)

Graves' orbitopathy tends to be more severe in smokers

Decreased effectiveness of orbital radiotherapy and/or high-dose glucocorticoids for moderately severe Graves' orbitopathy in smokers

Lower risk of developing diplopia and proptosis in past smokers than in current smokers

tobacco consumption, while thyroidologists of the second group mostly belonged to countries with an increasing tobacco consumption [9] (table 2).

Whether passive smoking may have the same impact on GO occurrence as active smoking is difficult to ascertain. However, in a recent ETA survey of GO in childhood, the highest proportion $(>35 \%)$ of Graves' children with orbitopathy was in countries where the prevalence of smokers among teenagers was also highest $(\geq 25 \%)$ [10] (table 2 ). The interesting finding was that in the latter countries the majority (52\%) of Graves' children with orbitopathy were $\leq 10$ years of age, suggesting (although not proving) owing to their young age and, therefore, the unlikelihood of active smoking - that passive exposure to smoking may also contribute to the development of GO [10].

Does smoking withdrawal have an impact on the risk of developing GO? Randomized controlled studies on this issue are lacking, but in a prospective study, the relative risk of developing diplopia was 1.8 in current smokers of 1-10 cigarettes/ day, which increased progressively to 7.0 at a dose $>20$ cigarettes/day, but decreased to 1.9 in past smokers of $>20$ cigarettes/day [11] (table 2). This presently is the best, although not conclusive, evidence that quitting smoking may prevent the occurrence of the orbitopathy in Graves' patients.

\section{What Can Be Done in Terms of Secondary Prevention of Graves' Orbitopathy?}

Many Graves' patients have subclinical orbitopathy, detectable only by imaging (CT scan, MRI) or other specialist investigations, such as measurement of intraocular pressure in upward gaze, but progression to overt eye disease of different severity may occur. This is probably accounted for, at least in part, by the natural history of GO, because orbitopathy may either precede Graves' hyperthyroidism, occur 
concomitantly, or follow it even after a long time interval [12]. The latter situation, however, may be due to factors affecting GO course, which can be corrected.

Thyroid dysfunction contributes to progression from subclinical to clinically overt GO. In a 5-month follow-up study, orbitopathy remained stable in patients already euthyroid (under antithyroid drug therapy) at the time of first observation; at variance, eye changes progressively improved in patients whose initial hyperthyroidism was subsequently controlled by treatment [13]. In a large consecutive-entry study, prevalence of uncontrolled hyperthyroidism was greater in patients with more severe ocular changes than in those with milder ocular involvement [14]. Hypothyroidism may affect the course of GO as well. In a series of 30 patients referred for severe orbitopathy, half developed eye disease after a period of hypothyroidism [15]. Thus, prompt restoration of normal thyroid function is a required intervention to hinder GO progression and/or contribute to its amelioration, and should be achieved as early as possible both in patients with asymptomatic orbitopathy (secondary prevention) and in those with clinically overt orbitopathy (tertiary prevention). That early diagnosis and treatment of hyperthyroidism probably is effective as secondary GO prevention is indirectly supported (although not proven) by the observation that GO prevalence in newly diagnosed Graves' disease has declined in the last decades [16]. In a recent randomized placebo-controlled of patients with mild GO, the addition of the antioxidant agent, selenium selenite (100 mg b.i.d.), to antithyroid drug treatment was associated with a better outcome in terms of eye involvement and quality of life compared to pentoxifylline or placebo [see chapter by Salvi et al., pp. 111-119]. Accordingly, selenium should be considered as tool for secondary prevention of GO.

What about the effects of treatments for hyperthyroidism on the orbitopathy? Neither antithyroid drugs nor thyroidectomy are disease-modifying treatments. In other words, they do not alter GO natural history [17]. Conversely, radioiodine treatment causes progression of pre-existing orbitopathy (rarely its de novo occurrence) in about $15 \%$ of cases [18]. Worsening of eye disease is often transient, and is more likely in patients who smoke, have severe hyperthyroidism, high anti-TSH receptor antibody titres, or whose post-radioiodine hypothyroidism is not promptly corrected by L-thyroxine replacement [19] (table 3). Thus, radioiodine therapy is the only treatment for hyperthyroidism associated with a small risk of GO progression. This seems unlikely, if the above risk factors are absent, in patients with no ocular signs prior to radioiodine administration, or whose eye disease is inactive after previous glucocorticoid treatment [20]. In any case, radioiodine, an effective treatment for hyperthyroidism, can safely be used in patients with $\mathrm{GO}$ or at risk of developing it, because progression can be prevented by a relatively short-course of oral glucocorticoids at moderate doses (25-30 mg prednisone daily, withdrawn over $6-12$ weeks) $[18,21,22]$. A recent matched retrospective study has shown that lower doses of oral prednisone $(0.2 \mathrm{mg} / \mathrm{kg}$ body weight as the initial dose, withdrawn over 6 weeks) are equally effective and better tolerated [23].

Smoking is associated with a higher relapse rate of hyperthyroidism after antithyroid drug treatment. It is, therefore, conceivable, albeit not proven, that smoking 
Table 3. Risk factors involved in radioiodine-associated progression of Graves' orbitopathy

Pre-existing and active Graves' orbitopathy

Smoking

Severity of hyperthyroidism

High TSH receptor antibody titres

Uncorrected post-radioiodine hypothyroidism

withdrawal may increase the chance for Graves' hyperthyroidism to go into permanent remission (table 2). Because thyroid hyperfunction and related autoimmune reactions have a negative impact on GO, it can be inferred that refraining from smoking in patients treated with antithyroid drugs for hyperthyroidism may be secondary prevention of the progression of subclinical to clinically manifest orbitopathy.

\section{What about Tertiary Prevention of Graves' Orbitopathy?}

Once GO is overt, tertiary prevention consists of measures aimed at avoiding complications and minimizing disability. In mild orbitopathy, general measures - such as artificial tear drops to lubricate the eyes, eye pads at night to prevent risks associated with exposure keratitis, and prisms to control mild (but invalidating) diplopia - may be effective [1]. In moderately severe orbitopathy, either medical treatments (systemic high-dose glucocorticoids and/or orbital radiotherapy) or surgery (orbital decompression) are indicated, the choice of treatment depending on GO severity and activity, to arrest further progression of eye disease and to achieve, if possible, its regression [24-26]. It is worth underscoring that smoking decreases the effectiveness of glucocorticoids and irradiation $[27,28]$; accordingly, smoking withdrawal is also a form of tertiary prevention. In sight-threatening orbitopathy (dysthyroid optic neuropathy), high-dose glucocorticoid treatment or, in case of failure, orbital decompression is urgently required to avoid possible sight loss [1]. In inactive orbitopathy, rehabilitative surgery -, i.e. orbit surgery for residual proptosis, eye muscle surgery for strabismus, and eyelid surgery for lid retraction -, has cosmetic and functional indications to correct residual disability [24, 25].

\section{What Should One Do when Talking to a Graves' Orbitopathy Patient Who Smokes?}

It is evident that smoking is the most important risk factor for GO occurrence and progression. Accordingly, although data on the effects of smoking withdrawal are 
scant, circumstantial evidence suggests that refraining from smoking is a fundamental intervention in terms of primary, secondary, and tertiary prevention of the disease. Therefore, Graves' patients, independently of the presence or absence of GO and its severity, must be urged to quit smoking. A clear explanation of risks of severe eye disease, profound effects of (not necessarily severe) orbitopathy on daily activities and quality of life, reduced effectiveness of medical treatments (if required), and a strong statement that smoking affects all the above is mandatory. Showing pictures of patients with severe ocular manifestations may help. Physicians should also underscore the fact that if the patient quits smoking, there are good chances that eye disease will not deteriorate, may even improve, and become more responsive to planned treatments. The use of patient information leaflets may be helpful. However, scaring patients or enhancing their motivations may be not enough to convince them because refraining from smoking is not easy. Therefore, patients who are unable to quit smoking by themselves should be referred to professional stop-smoking clinics, organizations and groups where they can receive counselling, behavioural therapies, or pharmacological treatments.

\section{Acknowledgements}

This work was partially supported by grants from the Italian Ministry of Education, University and Research (MIUR, Rome; PRIN n. 20074X8RKK) and the University of Insubria, Varese, Italy.

\section{References}

$>1$ Bartalena L, Pinchera A, Marcocci C: Management of Graves' ophthalmopathy: reality and perspectives. Endocr Rev 2000;21:168-199.

2 Oberman A: Principles of preventive health care; in Goldman L, Ausiello D (eds): Cecil Textbook of Medicine, ed 22. Philadelphia, Saunders, 2004, pp 44-46.

>3 Bahn RS: Graves' ophthalmopathy. N Engl J Med 2010;362:726-738.

4 Wiersinga WM, Bartalena L: Epidemiology and prevention of Graves' ophthalmopathy. Thyroid 2002;12:855-860.

5 Bartalena L, Marcocci C, Pinchera A: Graves' ophthalmopathy: a preventable disease? Eur J Endocrinol 2002;146:457-461.

6 Holm IA, Manson JAE, Michels KB, Alexander EK, Willett WC, Utiger RD: Smoking and other lifestyle factors and the risk of Graves' hyperthyroidism. Arch Intern Med 2005;165:1606-1611.

7 Prummel MF, Wiersinga WM: Smoking and risk of Graves' disease. JAMA 1993;269:479-482.
8 Bartalena L, Martino E, Marcocci C, Bogazzi F, Panicucci M, Velluzzi F, Loviselli A, Pinchera A: More on smoking habits and Graves' ophthalmopathy. J Endocrinol Invest 1989;12:733-737.

$\checkmark 9$ Weetman AP, Wiersinga WM: Current management of thyroid-associated ophthalmopathy in Europe: results of an international survey. Clin Endocrinol (Oxf) 1998;49:21-28.

10 Krassas GE, Segni M, Wiersinga WM: Childhood Graves' ophthalmopathy: results of a European questionnaire study. Eur J Endocrinol 2005;153:515-521.

11 Pfeilschifter J, Ziegler R: Smoking and endocrine ophthalmopathy: impact of smoking severity and current versus lifetime cigarette consumption. Clin Endocrinol (Oxf) 1996;45:477-481.

12 Marcocci C, Bartalena L, Bogazzi F, Panicucci F, Pinchera A: Studies on the occurrence of ophthalmopathy in Graves' disease. Acta Endocrinol (Copenh) 1989;120:473-478.

13 Prummel MF, Wiersinga WM, Mourits MP, Koornneef L, Berghout A, van der Gaag R: Amelioration of eye changes of Graves' ophthalmopathy by achieving euthyroidism. Acta Endocrinol (Copenh) 1989;121(suppl 2):185-189. 
14 Prummel MF, Wiersinga WM, Mourits MP, Koornneef L, Berghout A, van der Gaag R: Effect of abnormal thyroid function on the severity of Graves' ophthalmopathy. Arch Intern Med 1990;150:10981101.

$\checkmark 15$ Karlsson AF, Westermark K, Dahlberg PA, Jansson R, Enoksson P: Ophthalmopathy and thyroid stimulation (letter). Lancet 1989;ii:691.

16 Kendall-Taylor P, Perros P: Clinical presentation of thyroid associated orbitopathy. Thyroid 1998;8:427428.

17 Marcocci C, Bruno-Bossio G, Manetti L, Tanda ML, Miccoli P, Iacconi P, Bartolomei MP, Nardi M, Pinchera A, Bartalena L: The course of Graves' ophthalmopathy is not influenced by near-total thyroidectomy: a case-control study. Clin Endocrinol (Oxf) 1999;51:503-508.

18 Bartalena L, Marcocci C, Bogazzi F, Manetti L, Tanda ML, Dell'Unto E, Bruno-Bossio G, Nardi M, Bartolomei MP, Lepri A, Rossi G, Martino E, Pinchera A: Relation between therapy for hyperthyroidism and the course of Graves' ophthalmopathy. N Engl J Med 1998;338:73-78.

19 Bartalena L, Tanda ML, Piantanida E, Lai A, Pinchera A: Relationship between management of hyperthyroidism and course of the ophthalmopathy. J Endocrinol Invest 2004;27:288-294.

20 Perros P, Kendall-Taylor P, Neoh C, Frewin S, Dickinson AJ: A prospective study of the effects of radioiodine therapy for hyperthyroidism in patients with minimally active Graves' ophthalmopathy. J Clin Endocrinol Metab 2005;90:5321-5323.

21 Bartalena L, Marcocci C, Bogazzi F, Panicucci M, Lepri A, Pinchera A: Use of corticosteroids to prevent progression of Graves' ophthalmopathy after radioiodine therapy for hyperthyroidism. $\mathrm{N}$ Engl J Med 1989;321:1349-1352.

22 Bartalena L: Glucocorticoids for Graves' ophthalmopathy: how and when. J Clin Endocrinol Metab 2005;90:5497-5499.
23 Lai A, Sassi L, Compri A, Marino F, Sivelli P, Piantanida E, Tanda ML, Bartalena L: Lower dose prednisone prevents radioiodine-associated exacerbation of initially mild or absent Graves' orbitopathy: a retrospective cohort study. J Clin Endocrinol Metab 2010;95;1333-1337.

24 Bartalena L, Baldeschi L, Dickinson A, Ecksten A, Kendall-Taylor P, Marcocci C, Mourits M, Perros P, Boboridis K, Boschi A, Currò N, Daumerie C, Kahaly GJ, Krassas GE, Lane CM, Lazarus JH, Marinò M, Nardi M, Neoh C, Orgiazzi J, Pearce S, Pinchera A, Pitz S, Salvi M, Sivelli P, Stahl M, von Arx G, Wiersinga WM: Consensus statement of the European Group on Graves' orbitopathy(EUGOGO) on management of GO. Eur J Endocrinol 2008;158: 273-285.

25 Bartalena L, Baldeschi L, Dickinson A, Ecksten A, Kendall-Taylor P, Marcocci C, Mourits M, Perros P, Boboridis K, Boschi A, Currò N, Daumerie C, Kahaly GJ, Krassas GE, Lane CM, Lazarus JH, Marinò M, Nardi M, Neoh C, Orgiazzi J, Pearce S, Pinchera A, Pitz S, Salvi M, Sivelli P, Stahl M, von Arx G, Wiersinga WM: Consensus statement of the European Group on Graves' orbitopathy(EUGOGO) on management of Graves' orbitopathy. Thyroid 2008;18:333-346.

26 Bartalena L, Tanda ML. Graves'ophthalmopathy. N Engl J Med 2009;360:994-1001.

27 Bartalena L, Marcocci C, Tanda ML, Manetti L, Dell'Unto E, Bartolomei MP, Nardi M, Martino E, Pinchera A: Cigarette smoking and treatment outcomes in Graves' ophthalmopathy. Ann Intern Med 1998;129:632-635.

28 Eckstein A, Quadbeck B, Mueller G, Rettenmeier AW, Hoermann R, Mann K, Steuhl P, Esser J: Impact of smoking on the response to treatment of thyroid associated ophthalmopathy. Br J Ophthalmol 2003; 87:773-776.

Prof. Luigi Bartalena

Division of Endocrinology, Department of Clinical Medicine University of Insubria, Ospedale di Circolo, Viale Borri, 57

IT-21100 Varese (Italy)

Tel. + 390332 278561, Fax + 390332 278358, E-Mail I.bartalena@libero.it 